\title{
Improved thermal performance of a large laminated lithium-ion power battery by reciprocating air flow
}

\author{
Shixue Wang ${ }^{1}$, Kaixiang $\mathrm{Li}^{1}$, Yuan Tian ${ }^{2,}{ }^{*}$, Junyao Wang ${ }^{1}$, Yukang $\mathrm{Wu}^{1}$, Shan $\mathrm{Ji}^{1}$ \\ ${ }^{1}$ Key Laboratory of Efficient Utilization of Low and Medium Grade Energy (Tianjin University), \\ Ministry of Education, Tianjin 300072, China \\ ${ }^{2}$ Institute of Energy and Sustainable Development, School of Engineering and Sustainable \\ Development, De Montfort University, Leicester LE1 9BH, UK
}

\section{Highlights}

- A reciprocating air system was applied to large laminated battery ingeniously.

- A DOD-associated timing was optimized for when to reverse air-flow direction.

- A uniform-temperature distribution was achieved by the optimized reversing strategy.

- The temperature rise was restrained by the variation of cell layout and air flow rate.

\begin{abstract}
:
Thermal safety issues are increasingly critical for large-size laminated Lithium-Ion Batteries (LIBs). Despite a number of investigations conducted on the Battery Thermal Management System (BTMS) with reciprocating air-flow cooling, large laminated power LIBs are still not sufficiently investigated, particularly in the view of battery thermal characteristics. The present study investigates the thermal behaviors of an air-cooled NCM-type LIB ( $\mathrm{LiNi}_{1-\mathrm{x}-\mathrm{y}} \mathrm{Co}_{\mathrm{x}} \mathrm{Mn}_{\mathrm{y}} \mathrm{O}_{2}$ as cathode) from an experimental and systematic approach. The temperature distribution was acquired from different Depth of Discharge (DOD) by the infrared imaging (IR) technology. A reciprocating air-flow cooling method was proposed to restrict the temperature fluctuation and homogenize temperature distribution. Results showed that there was a remarkable temperature distribution phenomenon during the discharge process, the temperature distribution was affected by direction of air-flow. Forward air-flow (from current collector side to lower part of battery) was always recommended at the beginning of the discharge due to the thermal characteristics of the battery. After comprehensive consideration on battery temperature limit and cooling effect, the desired initial reversing timing was about 50\% DOD at $3 \mathrm{C}$ discharge rate. Different reversing strategies were investigated including isochronous cycles and aperiodic cycles. It was found that the temperature non-uniformity caused by heat accumulation and concentration was mitigated by reciprocating air-flow with optimized reversing strategy.
\end{abstract}

Keywords: Large-size lithium-ion battery; Reciprocating air-flow; Temperature distribution; Infrared temperature measurement 


\section{Nomenclature}

$\begin{array}{cl}\text { A } & \text { Tab distance (mm) } \\ \text { B1 } & \text { Cathode tab width (mm) } \\ \text { B2 } & \text { Anode tab width (mm) } \\ \text { C } & \text { Anode tab apothem (mm) } \\ \text { D } & \text { Sealant height (mm) } \\ \text { H } & \text { Humidity (\%) } \\ \text { h } & \text { Cell height (mm) } \\ \text { h1 } & \text { Tab height (mm) } \\ \text { h2 } & \text { Cell top sight height }(\mathrm{mm}) \\ \text { h3 } & \text { Cell bottom side height }(\mathrm{mm}) \\ \mathrm{T} & \text { Cell thickness (mm) } \\ \mathrm{T}_{\text {amb }} & \text { Ambient temperature }\left({ }^{\circ} \mathrm{C}\right) \\ \mathrm{T}_{\mathrm{b}} & \text { Backward air flow cycle }(\mathrm{s}) \\ \mathrm{T}_{\mathrm{f}} & \text { Forward air flow cycle }(\mathrm{s}) \\ T_{h} & \text { The highest temperature }\left({ }^{\circ} \mathrm{C}\right) \\ T_{i} & \text { The initial temperature }\left({ }^{\circ} \mathrm{C}\right) \\ T_{i n c} & \text { The maximum temperature increase }\left({ }^{\circ} \mathrm{C}\right) \\ T_{l} & \text { The lowest temperature }\left({ }^{\circ} \mathrm{C}\right) \\ \Delta T_{\text {max }} & \text { The maximum temperature difference }\left({ }^{\circ} \mathrm{C}\right) \\ T_{\text {max }} & \text { The highest temperature point in IR image }\left({ }^{\circ} \mathrm{C}\right) \\ T_{\text {var }}^{2} & \text { The temperature variance }\left({ }^{\circ} \mathrm{C}\right) \\ \mathrm{W} & \text { Width of battery (mm) } \\ \text { W1 } & \text { Side width (mm) } \\ & \end{array}$

\section{Acronyms and Abbreviations}

BTMS Battery Thermal Management System

C Discharge rate

CC-CV Constant voltage and constant current

CFD Computational fluid dynamics

DOD Depth of Discharge

EV Electric Vehicles

IR Infrared imaging

LIBs Lithium-Ion Batteries

PCM Phase-change material

PHEV Plug-in hybrid electric vehicles

NCM $\quad \mathrm{Ni}_{1-\mathrm{x}-\mathrm{y}} \mathrm{Co}_{\mathrm{x}} \mathrm{Mn}_{\mathrm{y}} \mathrm{O}_{2}$ 


\section{Introduction}

Lithium-ion batteries (LIBs) have great potential for Electric Vehicles (EV) due to high energy density and long cycle life [1]. Nevertheless, since the performance and life of lithium-ion batteries are very sensitive to temperature, it is important to maintain the proper temperature range. local overheating and large temperature variation during the charging and discharging processes are still critical challenges for the laminated LIBs [2]. In fact, the thermal issues of large lithium-ion power batteries have always been a bottleneck which restricts the development of the EV. The thermal imbalance among the cells significantly affects short and long term performances of the vehicle battery systems. According to the Arrhenius law of battery electrochemistry, the battery reaction increases exponentially with the battery cell temperature. As a result, cells in high temperature degrade more quickly than that in proper temperature. In addition, the thermal safety of LIBs is becoming increasingly critical, as it gets much more difficult to curb the thermal runaway of large power LIBs caused by the local overheating compared to ordinary batteries [3]. Thermal runaway is highly hazardous with every effort made to prevent it from happening.

In order to solve the thermal related issues of LIBs and improve thermal safety performance, numbers of experimental studies have been conducted to investigate the thermal management of battery packs. In all kinds of thermal management systems, liquid cooling, heat pipe and PCM thermal management systems have drawn extensive attention [4-7], however, the traditional air-cooling system is still highly preferred by most of EVs manufacturers due to low manufacturing cost and energy loss, simple layout requirement and superior security. Lu et al. [8] designed a thermal resistance model of single irregular air passage to validate the numerical scheme. It was found that the appropriate cooling channel size of $1 \mathrm{~mm}$ for 18650 lithium-ion battery was achieved based on three key parameters: the maximum temperature, the space utilization and the energy efficiency factor. Wang et al. [9] created a three-dimensional computational fluid dynamics (CFD) model to discuss the factors that influence the cooling capability of forced air cooling. The temperature distributions of batteries were quantitatively described and an optimized intercell distance in battery module structure was recommended. Fan et al. [10] investigated a battery module of plug-in hybrid electric vehicles (PHEV) by three-dimensional transient thermal analyses. It was concluded that considering the variety of the design change options and their combinations, the temperature gradients along the air flow direction can be affected but are generally unavoidable. Giuliano et al. [11] designed an air-cooled thermal management system employing metal-foam based heat exchanger plates. It was found that an airflow of $1100 \mathrm{mls}^{-1}$ per cell restricts the temperature rise of the coolant air to less than $10^{\circ} \mathrm{C}$ over ambient at 200 A charge-discharge cycles. The results indicate that aircooled systems can be an effective method for the thermal management of automotive battery packs. Zhu et al. [12] developed an electrochemical-thermal model of the Li-ion battery pack with a forced aircooling system based on a porous electrode and concentrated solution theory. The developed model was verified by charge/discharge cycling experiments under natural and forced convection conditions. 
The conventional battery air cooling systems utilize the one-directional air flow moving from the inlet and outlet of the battery cooling systems. As a result of the convective heat transfer along the air stream, the air temperature at the outlet is always higher than the inlet and the downstream cells near to the outlet are likely hotter than the upstream cells. The traditional air-cooling system has a great effect on maximum temperature rise. However, the temperature of air flow will increase continually along air flow channel and heat transfer effect was not ideal at the end part of flow channel, thus a huge temperature difference was formed within battery pack. Due to this highly hazardous phenomenon, reciprocating air-flow cooling method was proposed to restrict the temperature gradients. The basic principle of reciprocating or directional air-flow cooling was periodically reversing the direction of air flow or change air flow path. Studies have shown that reciprocating air-flow cooling method has postive effect on uniform temperature distribution of batteries. Studies that improved the cooling performance of the battery by changing the air flow path listed as follows: Mahamud et al. [13] studied a reciprocating cooling system that periodically reverses the flow of air to mitigate the inherent temperature uniformity problem of existing unidirectional air flows systems. The numerical results show that the reciprocating flow of a 120 second period can reduce temperature difference of battery cell by $72 \%$ and the maximum cell temperature by $1.5^{\circ} \mathrm{C}$ compared to unidirectional flow method due to the thermal redistribution and disturbance of the boundary layers formed in the cell. Yu et al. [14] proposed a new BTMS that includes a common air channel in which air flows in one direction, an air channel at the bottom of the pack with vertical turning air channels and jet holes for mitigating the heat accumulations in the battery pack. Research shows that the proposed system has significantly improved heat accumulation in the intermediate cells and $\Delta T_{\max }$ in each cell did not exceed $5^{\circ} \mathrm{C}$. Lu et al. [15] numerically investigated air cooling performance in two kinds of flow paths (15 and 59 vents) and air flow rates through a densely packed battery box with 252 cylindrical Li-ion batteries and five air baffles. They found that the densely packed battery box with 59 vents further reduced $T_{i n c}$ and $\Delta T_{\max }$ compared to the 15 vents case due to the improvement in effective heat transfer area between the air coolant and the battery surface. Liu et al. [16] designed a battery pack with reciprocating air-flow cooling system, and their experiment result showed that the temperature uniformity of battery increases by $12.1 \%$ and $62.4 \%$ respectively under discharge current rates of $1 \mathrm{C}$ and $13.33 \mathrm{C}$ (Charge and discharge rates of a battery are governed by C-rates, the capacity of a battery is commonly rated at $1 \mathrm{C}$, meaning that a fully charged battery rated at $1 \mathrm{Ah}$ should provide 1A for one hour). Na et al. [17] proposed a battery chamber with the cooling fluid in adjacent channels (multi-layered flow channel by partitions) flowing in the opposite direction, and their CFD results showed that the reverse layered flow improved the temperature uniformity and heat dissipation of the battery pack. He et al. [18] investigated the thermal management of a Li-ion battery module employing active temperature control and reciprocating cooling flow. Compared with results of unidirectional cooling flow, temperature non-uniformity was reduced from 4.2 to $1.0^{\circ} \mathrm{C}$ among cells and the amount of cooling flow consumed was reduced by $38 \%$.

Panchal et al. [19] designed a thermal management system with indirect liquid cooling using dual cold plates approach. This BTMS was created in the view of thermal characteristics of batteries. The thermal characteristics include the surface temperature distribution, heat flux, and the heat generation from 
batteries under various charge/discharge profiles. Panchal's team also make a contribution to the thermal modeling of temperature distributions in a prismatic lithium-ion battery [20]. The average surface temperature distributions with varying boundary conditions and the voltage profile at different discharge rates were comprehensive studied. The results show that the increased discharge rates result in increased surface temperature distributions on the principal surface of the battery and changing the operating or boundary conditions considerably affect the surface temperature distributions.

Saeidi et al. [21] presented a finite-volume-based computational study of transient laminar flow and heat transfer (neglecting natural convection) leading to periodic state within a square cavity. Experimental result show that the heat transfer is directly linked to the relation between the period of oscillation and the convection time scale. Khodadadi [22] investigated the analytic solution to the fully developed oscillatory fluid flow through a porous medium. The result show that when a highly viscous fluid undergoes slow pulsation in a high porosity medium, the phase lag vanishes and similar velocity profiles are observed. Siegel et al. [23] obtained the heat transfer solutions for pulsating laminar flow between parallel plates, the pulsations are caused bt superposing an oscillating pressure gradient on the steady driving pressure of the flow.

There was a remarkable temperature distribution of large battery during charge and discharge processes. An uneven temperature distribution originated from ionic concentration (different chemical reaction rates within different parts of a battery), uneven electrical resistance (different joule heat within different parts of a battery) and thermal resistance (different heat conduction rates within different parts of a battery). The uniformity of such temperature distributions is sensitive to both the heat flux (battery generated) and the air flow direction, so an all-sided consideration was needed to design a BTMS, the cooling methods should match up with thermal characteristics of battery. Several studies have been conducted on the validation of battery thermal characteristics. Kim et al. [24] developed a thermal model to study the effect of the electrode configuration on the thermal behaviors of a lithium-polymer battery. The results indicated that the current collecting tabs have a significant impact on the thermal behaviors of the battery. Dong [25] developed a numerical model for predicting the thermal behaviors of the lithium-ion battery. It was indicated that the increase in the temperature rising during the discharging process is higher than that during the charging process. In addition, it was found that the thermal behaviors were closely affected by the entropy change. Lee et al. [26] designed a flexible micro temperature/ voltage sensor and embedded into lithium-ion battery to acquire in situ temperature and voltage data. These temperature and voltage data are useful for improving the safety of lithium-ion batteries. Daud et al. [27] presented an electro-thermal model of a stack of three lithium ion batteries for automotive applications. This method can help to predict thermal behavior of battery cells inside a stack. Lei et al. [28] proposed a new heating method to improve low-temperature performance of battery. a lithium-ion battery is heated for some time and stopped heating for some time instead of continuing heating. Through simulation analysis and comparison, heating for $0.1 \mathrm{~s}$ and stopping heating for $0.3 \mathrm{~s}$ is most ideal to decrease the temperature gradient. 
Another major design variable that affects the cooling performance is the cell layout. Wang et al. [29] studied the thermal performance of battery modules in various cell layouts and in various fan position to improve temperature uniformity within the module. This study described the optimum cooling performance was obtained when the fan was located at the top of the module. They also developed a transient thermal model of a three-dimensional $5 \times 5$ rectangular cell array module based on an empirical heat source model to characterize the thermal behavior of the Li-ion battery. Yang et al. [30] discussed the thermal performances of the battery pack in which the arrangement of $6 \times 10$ cylindrical battery cells were in a staggered or aligned arrangement. Considering the temperature rise, temperature uniformity, power consumption and cooling index, battery pack with longitudinal interval and transverse interval of $34 \mathrm{~mm}$ and $32 \mathrm{~mm}$, respectively, were most reasonable.

From the above, reciprocating air-flow cooling was a valid approach of BTMS among all kinds of aircooling systems. Nevertheless, most researches were devoted to cylindrical battery, the application of reciprocating air-flow cooling method in large laminated power LIBs was not sufficiently investigated in existing research. Furthermore, for the cylindrical battery like the 18650 type, the temperature difference within a single cell was not prominent due to its winding structure and small size. However, the laminated type battery has a prominent temperature distribution because of its layer structure and large size. Most existing studies focus on the maximum temperature difference between cells, but the temperature difference within a single cell was neglected which is highly hazardous and significant in large cells. In addition, there was a certain thermal characteristic for each battery, the battery thermal behavior has a strong impact on thermal management effect. Therefore the BTMS design should match up with thermal characteristics of battery. Last but certainly not least, the battery chamber layout and other parameters such as air flow rate always have an immediate impact on the overall effect of thermal management. In the current study, a novel reciprocating air-flow cooling system was set up and experimentally studied. IR was adopted to investigate the thermal characteristics of laminated LIBs in different discharge rates and discharge depth under the condition of natural convection and reciprocating air-flow. Based on thermal characteristics of battery, the optimized control strategy of reciprocating airflow was found, also including desired initial direction and reversing timing, duration of isochronous cycle and aperiodic cycle. The basic setting of battery chamber layout and air flow rate were investigated thoroughly. It provides a valuable reference for further optimization and development of BTMS with reciprocating air-flow cooling.

\section{Experimental setup}

\subsection{Experimental system}

Fig. 1 shows the experimental system of the reciprocating air-flow cooling. The charge and discharge cycles were regulated by the battery testing system controlled by the programmable software. The current, voltage and resistant data can be collected in the experimental system. In the current study, the industrial infrared imager measures the thermal performance of the battery cell in the charge/discharge processes, while the T-type thermocouples calibrate the temperature measurement from IR. The measured temperature difference between the infrared imager and the thermocouples has a maximum tolerance of 
$0.1^{\circ} \mathrm{C}$ allowed. It was noted that the ambient light contains infrared ray and may form a reflection on the batteries surface to affect the measurement error of the infrared imager. Therefore, to eliminate such effects, a light shade was applied to block the infrared ray of the ambient light, as shown in Fig. 1. As a result, the maximum measurement error by the infrared imager was less than $0.1^{\circ} \mathrm{C}$. The infrared imager was fixed on a tripod and 1.2 meters from the surface of the battery cell and the lens, which was perpendicular to the measured surface. An IR glass sheet was adopted as the upper cover of battery chamber, the transmittance of IR glass was $90 \%$, and temperature attenuation caused by this was calibrated as well.

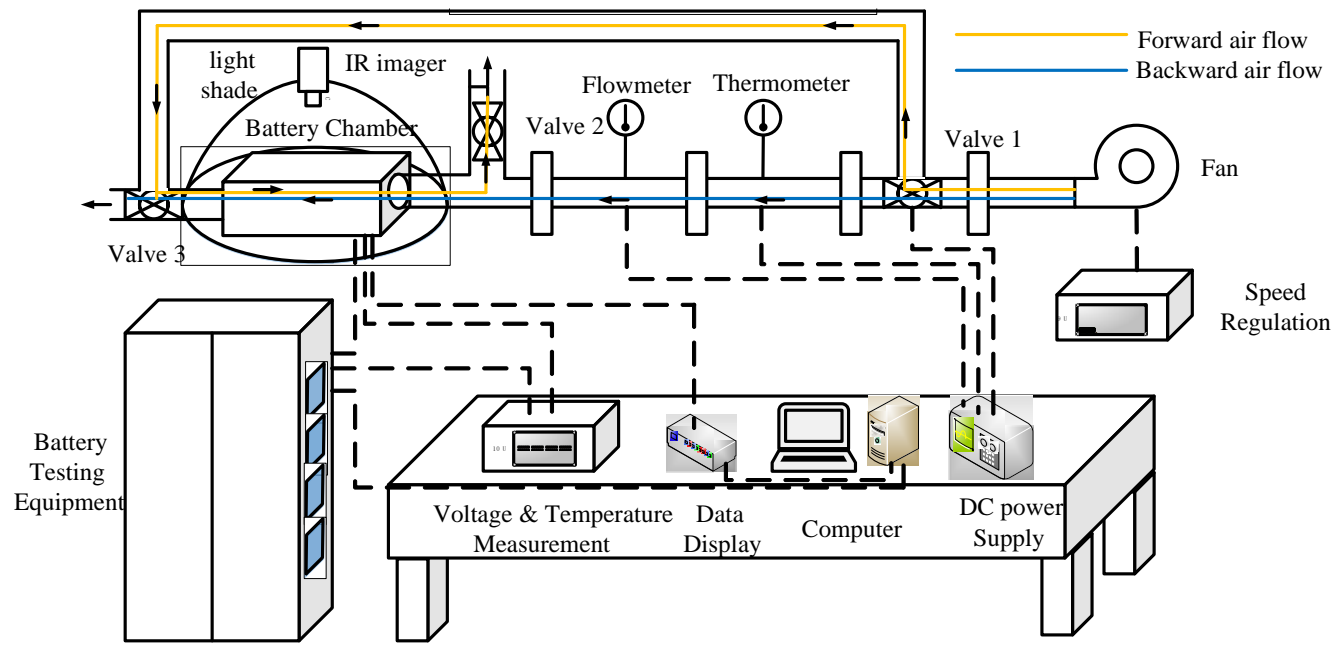

(a) Schematic diagram

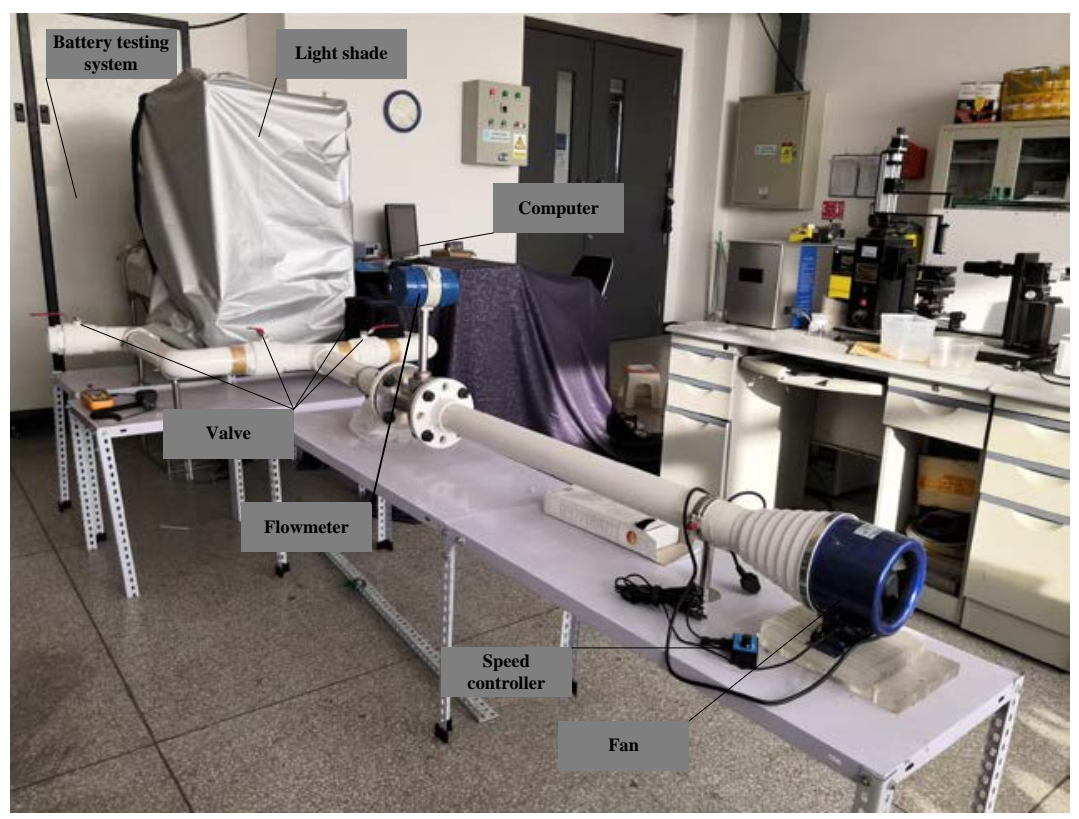

(b) test rig

Fig. 1. The experimental system.

The NCM pouch Cell $($ T $7.1 \mathrm{~mm} \times$ H $268 \mathrm{~mm} \times$ W $211 \mathrm{~mm}$ ) has a nominal capacity of 37 Ah and a rated voltage of $3.65 \mathrm{~V}$, as shown in Fig. 2 and Table 1. The positive current collecting tabs are made of aluminum in light color while the negative current collecting tabs are made of copper in dark color. The 
battery cell was fixed by adiabatic plastic clamps at the edge parts to ensure that the battery core was only exposed to air and not touched by any other experimental components.

Table 1. Battery cell parameters

\begin{tabular}{cccc}
\hline Items & Parameters(mm) & Items & Parameters(mm) \\
\hline Cell with (W) & 211 & Cell side width (W1) & 8 \\
Cell height (h) & 268 & Cell thickness (T) & 7.1 \\
Tab distance (A) & 100 & Cathode tab width (B1) & 60 \\
Anode tab width (B2) & 60 & Anode tab apothem (C) & 25.5 \\
Sealant height (D) & 2.0 & Tab height (h1) & 19 \\
Cell top sight height(h2) & 19 & Cell bottom side height (h3) & 8 \\
\hline
\end{tabular}
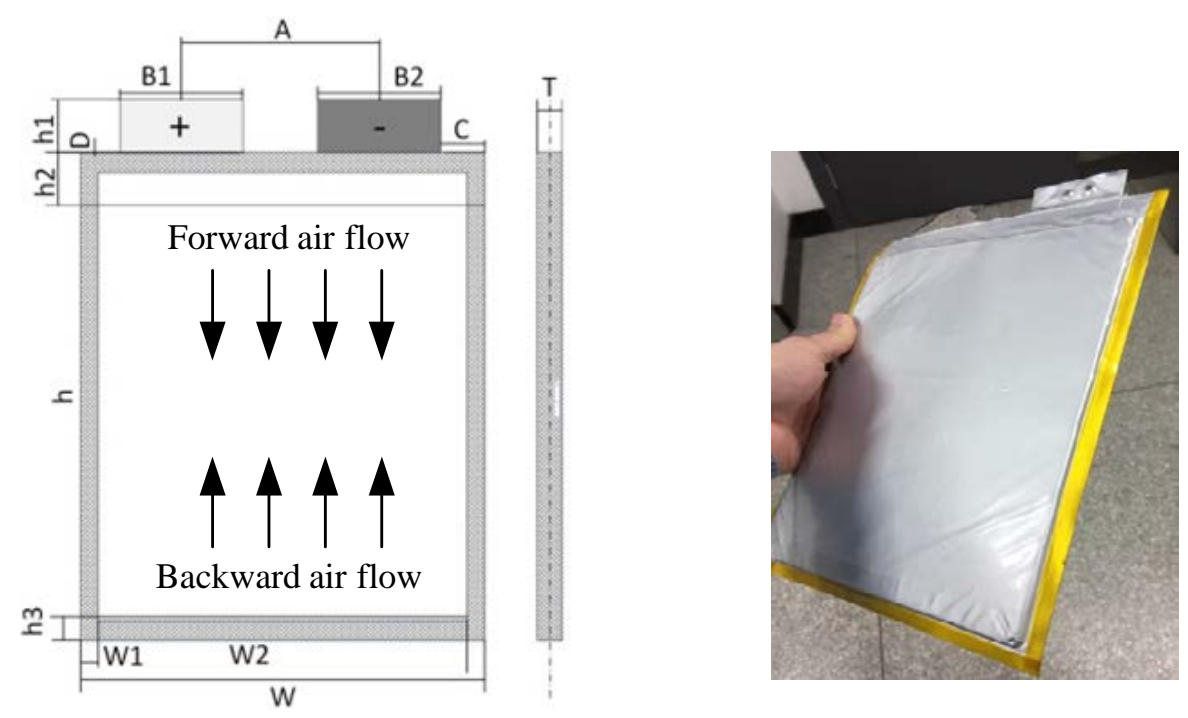

Fig. 2. Cell dimension schematic diagram.

\subsection{Experimental procedures}

This study aims to investigate the thermal behavior of the NCM battery cell in an air-cooling system. Therefore, the temperature of inlet air should be consistent during the experimental process. The ambient temperature was maintained at $25 \pm 0.5^{\circ} \mathrm{C}$ with the maximum variation of $1^{\circ} \mathrm{C}$. The battery temperature was measured under different charge/discharge rates with a cut-off voltage of $2.80 \mathrm{~V}$. The charge process follows the standard CC-CV method, in which a battery was initially charged at a constant current of 0.5 $\mathrm{C}$ until the voltage reaches $4.20 \mathrm{~V}$, and then charged at a constant voltage mode. The charging process was ended when the charging current drops to less than $0.05 \mathrm{C}$. The IR imager was of the VC360 model

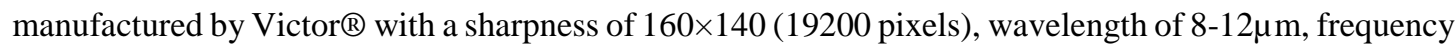
of $50 \mathrm{~Hz}$, sensitivity of $0.06^{\circ} \mathrm{C}$ at $30^{\circ} \mathrm{C}$ and a measurement range of -20 to $+350^{\circ} \mathrm{C}$. The parameters of IR imager are shown in Table 2, which was well calibrated and applied to measure the battery temperature in both charging and discharging processes. As the thickness of the laminated cell is rather thin, the maximum temperature difference within the battery cell along the thickness direction is safely neglected. 
The temperature distribution can be acquired by the infrared imager with a high accuracy and resolution since there was no physical contact and the influence of the ambient was eliminated by the shield in the experiment.

Table 2. Infrared imager parameters.

\begin{tabular}{cccc}
\hline Items & Parameter & Items & Parameter \\
\hline Environmental $\mathrm{T}_{\mathrm{amb}}$ & $25^{\circ} \mathrm{C}$ & Thermal infrared emissivity & 0.60 \\
Environmental $\mathrm{H}_{\mathrm{amb}}$ & $55 \%$ & Measuring distance & 1.2 meter \\
\hline
\end{tabular}

Measurement error of infrared imager was restricted by the following aspects: degree of accuracy, Ttype thermocouples were calibrated by ice water mixture in a vacuum bottle to ensure the difference between the measured value and the real temperature was no more than $0.1^{\circ} \mathrm{C}$; degree of precision, the measured temperature difference between the infrared imager and the thermocouples was allowed to be no more than $0.1^{\circ} \mathrm{C}$ during the experiments by adjusting battery surface emissivity; repeatability, at room temperature $\left(25^{\circ} \mathrm{C}\right)$, the surface temperature of the battery was measured several times, the measured temperature difference between the infrared imager and the thermocouples was no more than $0.1^{\circ} \mathrm{C}$; reproducibility, at $50^{\circ} \mathrm{C}$ high-temperature test chamber, the surface temperature of the battery was measured several times, the measured temperature difference between the infrared imager and the thermocouples is no more than $0.1^{\circ} \mathrm{C}$.

In the experimental system, cooling air was provided by a variable frequency fan. The direction of air flow was regulated by the valves shown in Fig. 1, where the path of forward air flow was defined as: fan (inlet) - valve 1 - valve 3 - outlet. The path of backward air flow was defined as: fan (inlet) - valve 1 valve 3- valve 2 - outlet.

\subsection{Key parameters}

The maximum temperature increase $\left(T_{i n c}\right)$ represents the temperature difference between the highest temperature $\left(T_{h}\right)$ and the initial temperature $\left(T_{i}\right)$ of the battery cell, which is defined and calculated by Eq. (1):

$$
T_{\text {inc }}=T_{h}-T_{i}
$$

The maximum temperature difference $\left(\Delta T_{\max }\right)$ denotes the temperature difference between $T_{h}$ and the lowest temperature $\mathrm{T}_{1}$, as shown in Eq. (2),

$$
\Delta T_{\max }=T_{h}-T_{l}
$$

The temperature variance $\left(T_{V a r}{ }^{2}\right)$ is defined to show the temperature uniformity of the battery cell. As the temperature distribution of the battery cell can be obtained from the infrared imager, $T_{V a r}{ }^{2}$ can be estimated by accounting the temperatures of each pixel dot and is described as:

$$
T_{\operatorname{Var}}^{2}=\sum_{i=1}^{n} f_{i}\left(x_{i}-\bar{x}\right)^{2}
$$

where $f_{i}$ denotes the frequency of a certain temperature range, and $\bar{x}$ denotes the average temperature. 


\section{Results and discussions}

\subsection{Thermal characteristics of the battery}

During the discharge process, heat generation rates were heterogeneously distributed in different parts of the battery cell. Therefore, the design of a thermal management system for the battery should be treated differently in the high-temperature zones and the low-temperature zones. The thermal characteristics of battery were experimentally studied under the condition of nature convection. Fig. 3 shows the IR images at a discharge rate of 3C at DOD of $10 \%, 30 \%, 50 \%, 70 \%$ and $90 \%$ respectively, which are used to demonstrate variations of the visualized temperature field. The non-uniform of temperature distribution occurred and variation of the temperature became stronger during the discharge process. According to these infrared images, in the condition of a high discharge rate, the upper part of the battery was the hightemperature region from the very beginning of discharge, and the lower part was the low-temperature region. Then with increase of DOD, the heat was conducted downward and the temperatures of the whole battery tended to be uniform. The experiment results illustrated the basic control strategy of reciprocating air-flow cooling for a large laminated battery. The direction of air flow at the beginning of discharge should be forward and then change at a certain DOD.

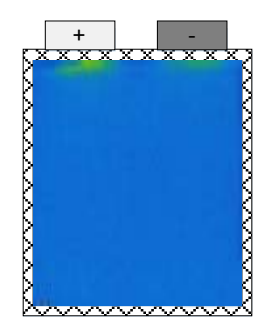

(a) $10 \%$ DOD

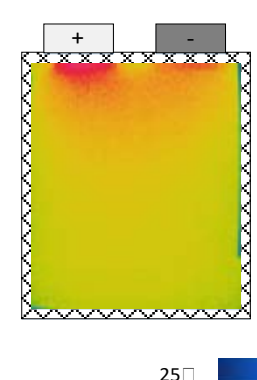

(b) $30 \%$ DOD

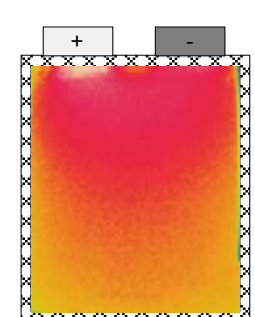

(c) $50 \%$ DOD

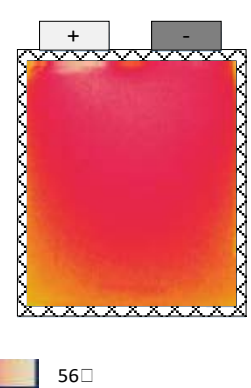

(d) $70 \%$ DOD

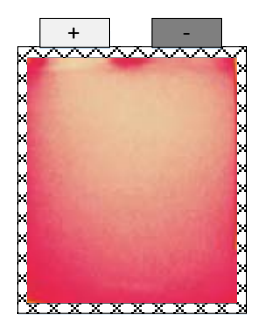

(e) $90 \% \mathrm{DOD}$

Fig. 3. Visualized temperature distribution with the increase of DOD (natural convection)

\subsection{Effect of air flow direction}

Fig. 4 shows the temperature variation of both forward and backward air flow. Then experiment was conducted under the condition of discharge rate of $3 \mathrm{C}$ and flow rate of $15 \mathrm{~m}^{2} / \mathrm{h}$. The thickness channel was set to $3 \mathrm{~mm}$. Fig. 4 (c) (d) was photographed near the end of discharge (90\% DOD), where the temperature distribution of battery surface was greatly changed compared to Fig. 3 (e) under natural convection cooling. Specifically, in the forward air flow case the high-temperature area was pushed down to the battery bottom, while the direction of temperature gradient was the opposite in the backward air flow case. Fig. 4 (a) (b) shows that both forward and backward air flow had a positive impact on heat management compared to the natural convection case. However, the forward air flow case performed better than the backward air flow in both maximum temperature rise and temperature difference, due to the thermal characteristics aforementioned. This also revealed that in a non-reciprocating air-flow system for a large pouch cell, the forward air flow was always preferred. 


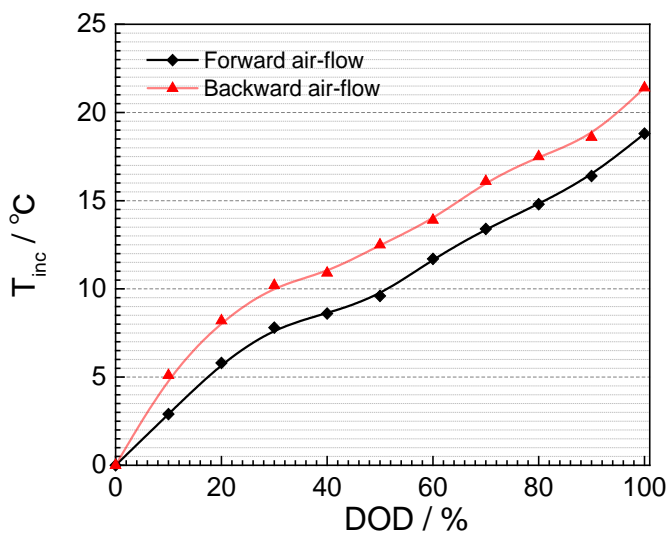

(a) $T_{i n c}$ of forward and backward air flow

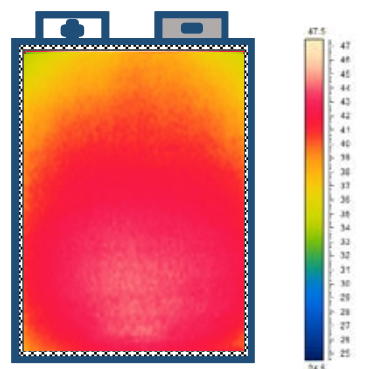

(c) Temperature distribution of forward air flow

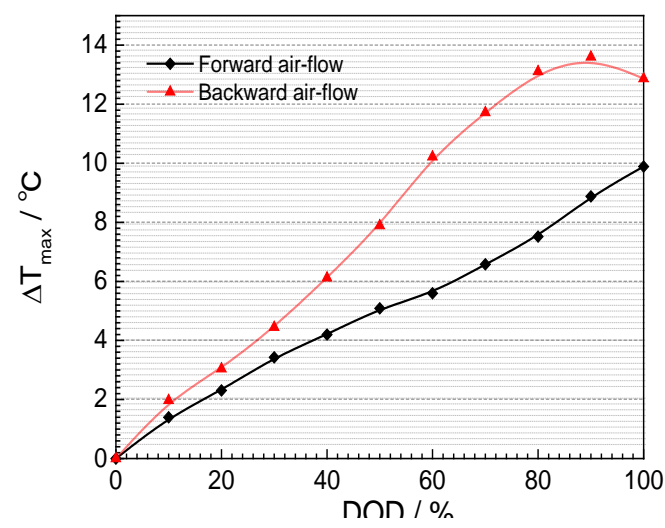

(b) $\Delta T_{\max }$ of forward and backward air flow

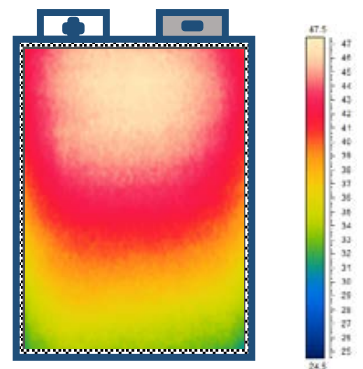

(d) Temperature distribution of backward air flow

Fig. 4. Effect of forward and backward air flow on temperature distribution

\subsection{Timing for reversing start}

As discussed above, the forward air flow was adopted from the very beginning of discharge according to battery thermal characteristics. Nevertheless, in the forward air flow case, the heat was accumulated along air-flow with $T_{i n c}$ and $\Delta T_{\max }$ showing an undesirable increasing trend. In order to deliver a uniformed temperature distribution, reciprocating air-flow was proposed. Experimental result showed that it was not ideal to start reciprocating air-flow from the very beginning of the discharge process. A systematic exploration was therefore conducted on when and how to start reversing air-flow. Here the experimental settings were exactly the same with section 3.2, the duration of the forward $\mathrm{T}_{\mathrm{f}}$ and backward air flow $\mathrm{T}_{\mathrm{b}}$ was equal and set as 30 seconds. Thus, a reciprocating cycle was 1 minute $\left(\mathrm{T}_{\mathrm{f}}=30 \mathrm{~s}, \mathrm{~T}_{\mathrm{b}}=\right.$ 30 s). the start timing of control groups was set as 30\%, 50\% and 100\% DOD, respectively. As shown in Fig. 5, the maximum temperature difference of all three reciprocating flow cases had remarkably decreased compared to the forward air flow case. However, there were differentiations in these cases. For the $30 \%$ DOD case, $\Delta T_{\max }$ was higher than that in the forward air flow case most of the time, indicating that it was not effective to prevent temperatures difference increase at an early stage of discharge. In the 80\% DOD case, temperatures difference decreased rapidly after the reverse due to large temperature difference between the upper and lower prat of battery ( $\Delta T_{\max }$ was about $7.1^{\circ} \mathrm{C}$ at $80 \%$ DOD). Compared to other cases, it had the lowest temperatures difference at the end of discharge. However, $\Delta T_{\max }$ was over the recommended $\Delta T_{\max }$ of $5^{\circ} \mathrm{C}$ most of the time. In the $50 \%$ DOD case, 
the curve of temperatures difference had the lowest temperatures difference between 50-85\% DOD compared to the other two cases. The growth rate of temperatures difference increased at the end of discharge indicating that an optimization of reversing strategy was needed to further improve temperature distribution.

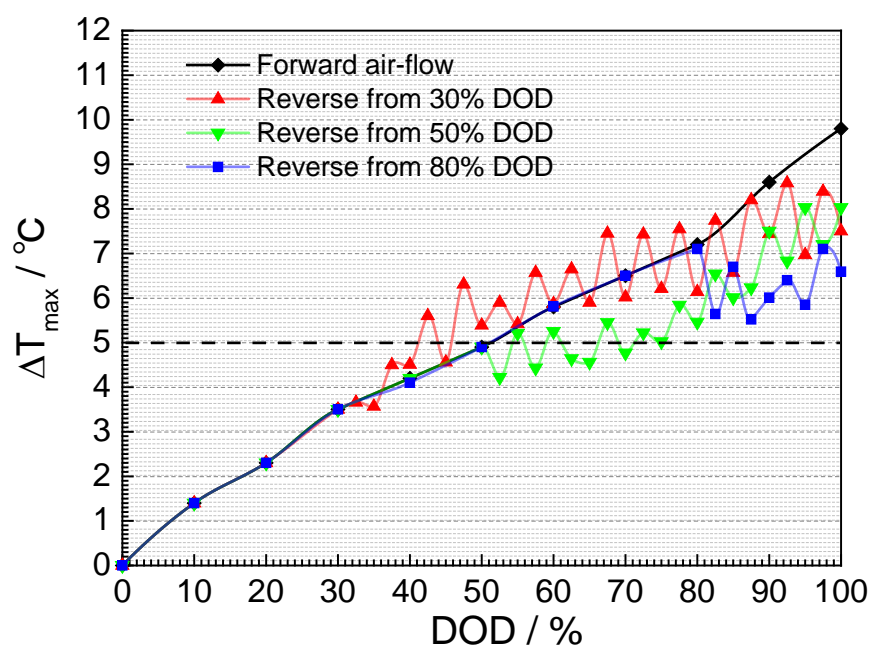

Fig. 5. Forward and reciprocating air-flow reversing start point of different DOD $\left(\mathrm{T}_{\mathrm{f}}=30 \mathrm{~s}, \mathrm{~T}_{\mathrm{b}}=30 \mathrm{~s}\right)$

\subsection{Effect of reciprocating cycle}

As seen in Fig. 6. (a), in the case of 50\% DOD, in end of discharge the growth rate of temperature difference decreased compared to the case in Fig. 5, this indicated that extended the period of $\mathrm{T}_{\mathrm{f}}$ appropriately may help to uniform temperature distribution, due to the high-temperature area located in the upper part of battery for majority DOD. Another set of experiment was conducted, reciprocating cycle was set as $T_{f}=60 \mathrm{~s}, T_{b}=30 \mathrm{~s}$. As demonstrated in Fig. 6. (b), it was indicated that the extension of $\mathrm{T}_{\mathrm{f}}$ period decreased the temperature difference efficiently in all isochronous cycle cases. The improvement was reflected in both final $\Delta T_{\max }$ cut down and the prolong duration of DOD that battery operated under $\Delta T_{\max }$ of $5^{\circ} \mathrm{C}$. For instance, the $50 \%$ DOD case in Fig. 6 (b) almost met the requirements of BTMS, while there was a fraction of DOD (80-100\% DOD) which did not fulfil $\Delta T_{\max }$ of $5^{\circ} \mathrm{C}$. Therefore, an aperiodic control strategy was proposed to further improve the temperature distribution of battery. The optimization goal of $\Delta T_{\max }$ was set as $5^{\circ} \mathrm{C}$ during the whole discharge process. 


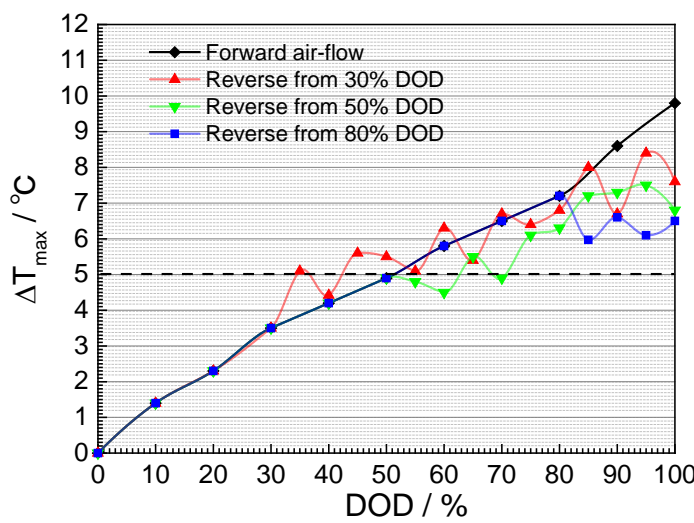

(a) $\mathrm{T}_{\mathrm{f}}=60 \mathrm{~s}, \mathrm{~T}_{\mathrm{b}}=60 \mathrm{~s}$

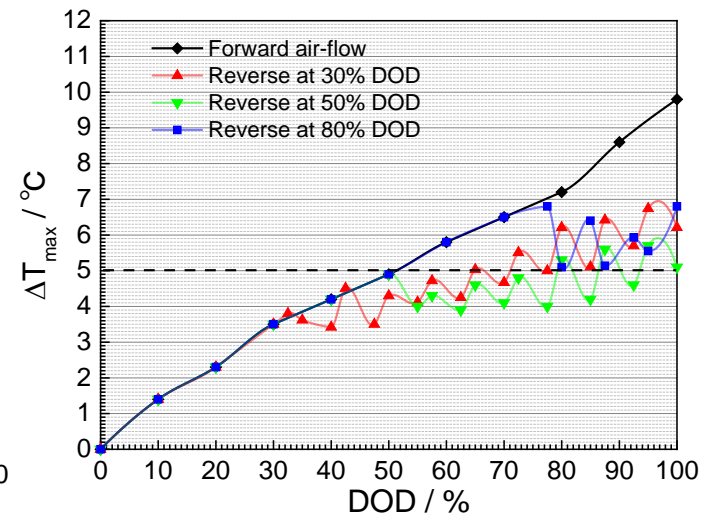

(b) $\mathrm{T}_{\mathrm{f}}=60 \mathrm{~s}, \mathrm{~T}_{\mathrm{b}}=30 \mathrm{~s}$

Fig. 6. Forward and reciprocating air-flow with different reversing conditions

It was observed from the cases above, the patterns of $\Delta T_{\max }$ changes were almost constant, there was a periodic fluctuation within a cycle, including a peak and trough. Pesaran [31] suggested that the maximum temperature difference from cell should be below $5^{\circ} \mathrm{C}$ to avoid adverse effects and prolong the service life of Li-ion batteries. Here an aperiodic reciprocating air-flow control strategy was designed by limiting the peak value of $4.9^{\circ} \mathrm{C}$, once the temperature difference reached $4.9^{\circ} \mathrm{C}$, the air-flow direction was reversed automatically. Experimental results are shown in Fig. 7 (a): after 9 directional changes $\Delta T_{\max }$ was restrained below $5^{\circ} \mathrm{C}$ successfully. A typical cycle was demonstrated in Fig. 8 (b) (c) and (d), for the point b the temperature difference was mainly caused by the high and low temperature area in the upper and low part of battery, then the forward airflow was applied to the cell pushing the high temperature area to move downward meanwhile with $\Delta T_{\max }$ beginning to drop. When $\Delta T_{\max }$ became wave troughs (point c) along with interchanged locations of high and low temperature area, $\Delta T_{\max }$ began to rebound. It was noticed that at the end of discharge process, a high-frequency direction reverse was required. This was due to the battery high temperature area moving downward to the central of battery and $\Delta T_{\max }$ become insensitive to air flow direction changes. Comparing Fig. 8 (b) and (d), it had the same $\Delta T_{\max }$ of $4.9^{\circ} \mathrm{C}$; however, due to different locations of high temperature area, the temperature gradient in Fig. 8 (d) was much higher than that in Fig. 8 (b). In the subsequent peaks of this curve the temperature gradient increased continuously, thus the effect of reciprocating air-flow on BTMS performance was degraded. Such an aperiodic reciprocating air-flow control strategy is also applicable to other $\Delta T_{\max }$ limit. The contrast experiments of aperiodic reciprocating air-flow were conducted under $\Delta T_{\text {max }}$ limits of $4^{\circ} \mathrm{C}, 4.5^{\circ} \mathrm{C}, 5.5^{\circ} \mathrm{C}$ and $6^{\circ} \mathrm{C}$, respectively. As shown in Fig. 7 (b), the times of air flow reversing increased rapidly with a stricter $\Delta T_{\max }$ limit. This also indicated that a high-frequency direction reverse of system was required when pursuing an ideal uniform temperature distribution. even so, due to the limitation of the valve rotation time and the inertia of air flow, the minimum reciprocating cycle was set as 20 seconds. 


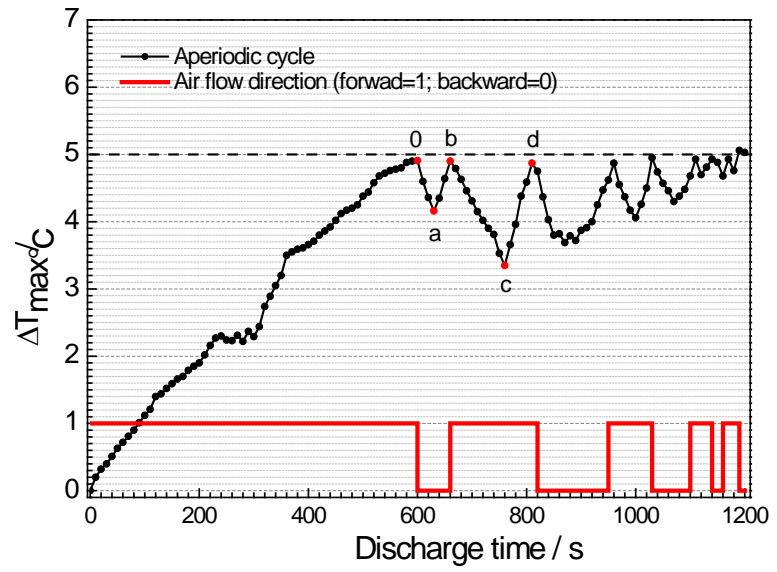

(a) $\Delta T_{\max }$ of $5^{\circ} \mathrm{C}$

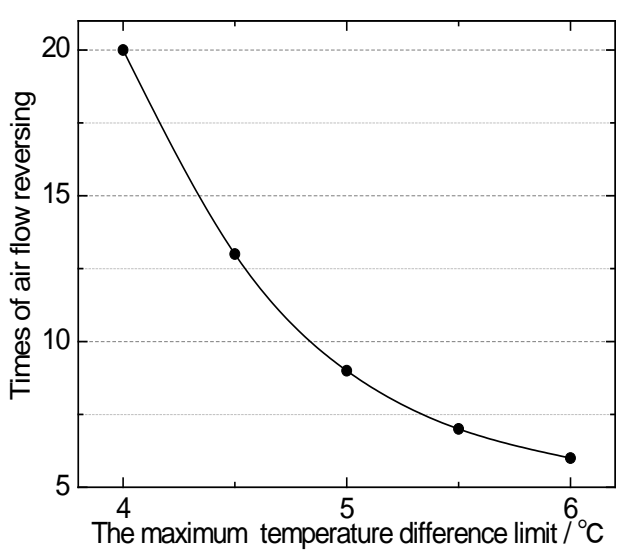

(b) Air flow reversing times \& $\Delta T_{\max }$ limit Fig. 7. Aperiodic reciprocating air-flow control strategy

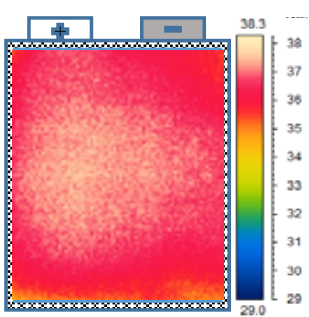

(a) Point a

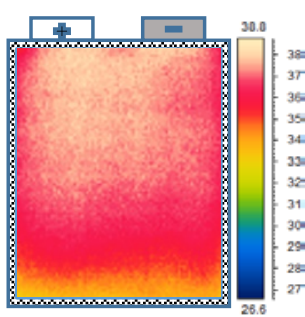

(b) Point b

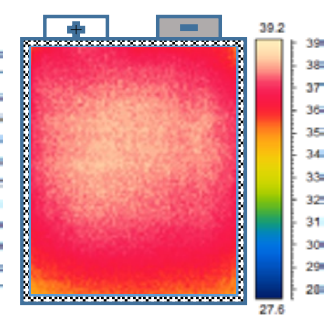

(c) Point c

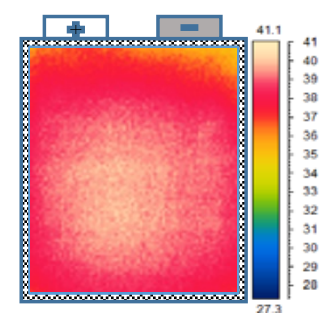

(d) Point d

Fig. 8. Optimized temperature distribution by aperiodic reciprocating air-flow

Fig. 8 shows the optimized temperature distribution by aperiodic reciprocating air-flow, with Fig. 8 (a) (b) (c) (d) corresponding to points a, b, c, d in Fig. 7, respectively. As mentioned above, such a control strategy was introduced according to actual circumstances. Points a and c were the troughs of temperature difference fluctuation, and showed an ideal homogeneous temperature distribution. Points b and d were the curve peaks and were also acceptable on temperature difference, $\Delta T_{\max }$ decreased $49.5 \%$ compared to forward air flow case. In this case, $\Delta T_{\max }$ was mainly caused by a small area of the low temperature.

For a comprehensive assessment of battery thermal condition, temperature variance was introduced to quantify the temperature fluctuation. As demonstrated in Table 3, under the same $\Delta T_{\max }$ of $4.9^{\circ} \mathrm{C}$, $T_{\operatorname{Var}}{ }^{2}$ of points $\mathrm{b}$ and $\mathrm{d}$ were 0.52 and 0.51 , respectively, which was much lower than point 0 . This indicated that reciprocating air-flow not only decreased temperature difference but also helped to homogeneous temperature distribution.

Table 3. Temperature values from infrared imager.

\begin{tabular}{ccc}
\hline Point & $\Delta \boldsymbol{T}_{\boldsymbol{m a x}}$ & $\boldsymbol{T}_{\boldsymbol{\text { Var }}}{ }^{\mathbf{2}}$ \\
\hline 0 (Initial reverse point) & $4.9^{\circ} \mathrm{C}$ & 0.61 \\
a & $4.1^{\circ} \mathrm{C}$ & 0.39 \\
b & $4.9^{\circ} \mathrm{C}$ & 0.52 \\
C & $3.4^{\circ} \mathrm{C}$ & 0.24 \\
\hline
\end{tabular}




\begin{tabular}{lll}
\hline $\mathrm{d}$ & $4.9^{\circ} \mathrm{C}$ & 0.51 \\
\hline
\end{tabular}

\subsection{Effect of flow rate and thickness of air channel}

Table 4 illustrated that, the reciprocating air-flow have a conspicuous and positive impact on temperature distribution but limited effect on $T_{i n c}$, which decreased by up to 5.8\% compared to the forward air-flow case. $T_{\text {inc }}$ cannot be improved by only relying on reciprocating air-flow or its control strategy. Like any traditional thermal management, $T_{i n c}$ can be optimized by adjusting the flow rate and thickness of the air channel. The effect of flow rate and channel thickness on $T_{i n c}$ and $\Delta T_{\text {max }}$ were experimentally explored. The layout of battery chamber was demonstrated in Fig.9, where the thickness of air channel was set as 2, 3 and $4 \mathrm{~mm}$ respectively. The experimental results shown in Fig. 10, it can be concluded that the $T_{\text {inc }}$ decreased with increased air flow rate, and under a certain air flow rate a smaller channel has better performance on $T_{i n c}$. However, in the terms of temperature difference, both less thickness of channel and higher rate flow have adverse effect. Due to the increased flow velocity, decreased section area of air flow resulted in increased convective heat transfer. Heat exchange with air is performed via forced convection which depends on air velocity, The air velocity in different channel and air flow rate shown in Table 5. There were more factors to consider when designing a BTMS with reciprocating airflow, besides the tradeoff of $T_{i n c}$ and $\Delta T_{\text {max }}$. For example, both thinner channel and higher rate flow require a higher energy consumption of air blower. As the air flow velocity was increased, the convective heat transfer on the cells was expected to increase, thus the cell temperatures would decrease but at the expense of higher pressure drop and pumping power. Furthermore, the channel thickness may affect the size of battery pack directly, for instance, $14.3 \%$ increase in battery pack volume for every $1 \mathrm{~mm}$ increase in air channel thickness. This may lead to a loose structure and decrease energy density of battery pack. For practical engineering applications, the trade-offs and optimization between the thermal load, weight and volume should be further investigated.

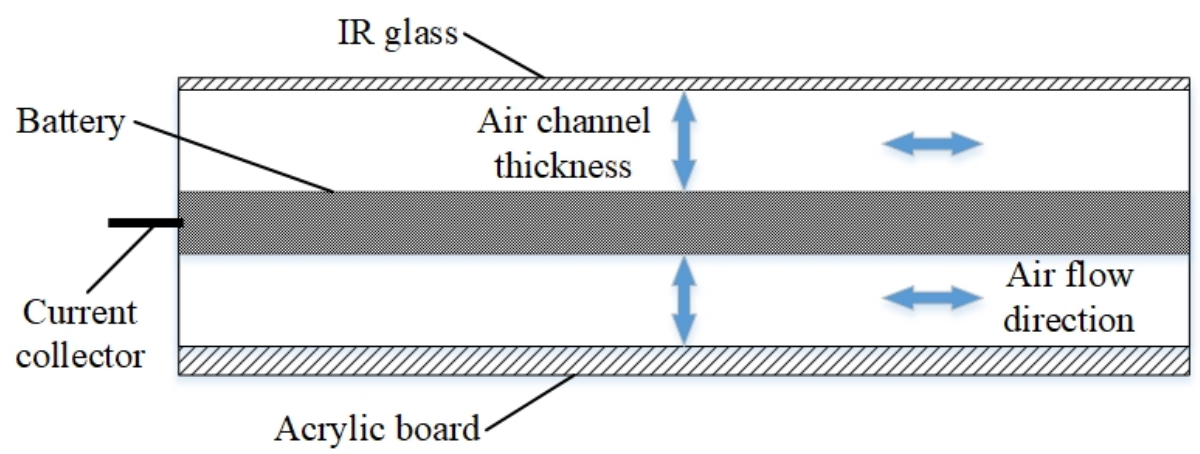

Fig. 9. Side view of the battery cooling chamber

Table 4. The maximum temperature in different reciprocating cases (the same condition as section 3.2)

\begin{tabular}{cccc}
\hline $\mathrm{T}_{\mathrm{f}}$ and $\mathrm{T}_{\mathrm{b}}$ & \multicolumn{3}{c}{ Maximum temperature $/{ }^{\circ} \mathrm{C}$} \\
\cline { 2 - 4 } & 30\% DOD start & $50 \%$ DOD start & 80\% DOD start \\
\hline 30s-30s & 42.5 & 43.0 & 43.4 \\
$60 \mathrm{~s}-60 \mathrm{~s}$ & 43.5 & 43.6 & 43.9
\end{tabular}




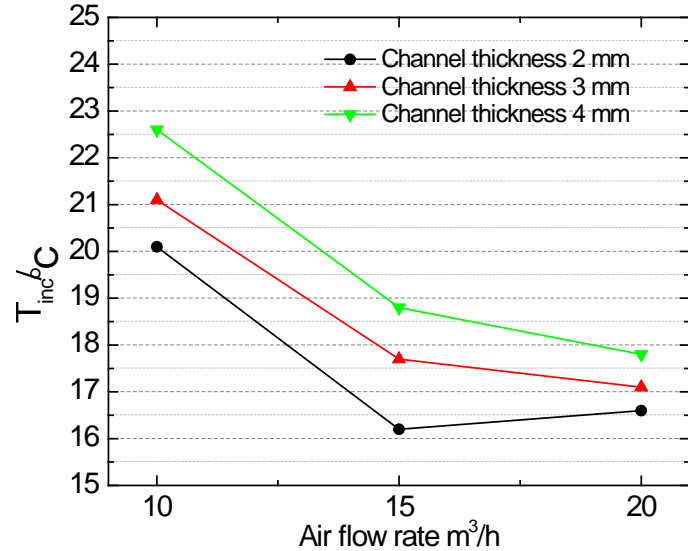

(a) $T_{i n c}$

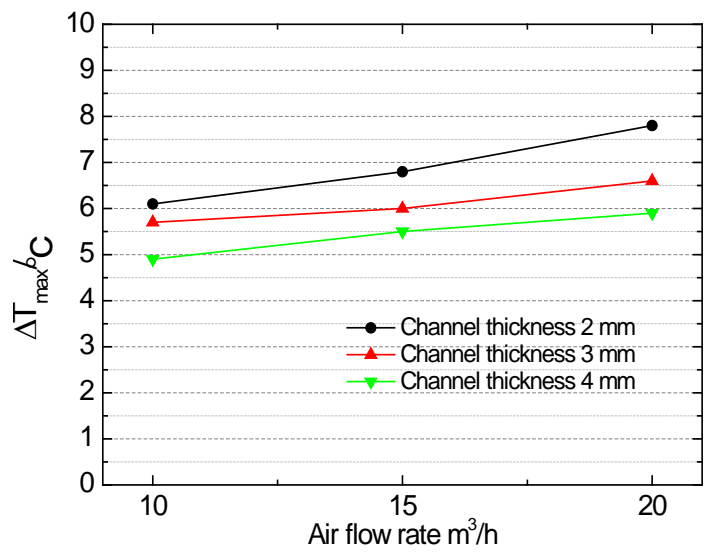

(b) $\Delta T_{\max }$

Fig. 10. Effect of flow rate and channel thickness on the maximum temperature rise and difference

Table 5. The air velocity in different channel and air flow rate.

\begin{tabular}{|c|c|c|c|}
\hline Air flow rate & $10 \mathrm{~m}^{3} / \mathrm{h}$ & $15 \mathrm{~m}^{3} / \mathrm{h}$ & $20 \mathrm{~m}^{3} / \mathrm{h}$ \\
\hline $2 \mathrm{~mm}$ & $6.58 \mathrm{~m} / \mathrm{s}$ & $9.31 \mathrm{~m} / \mathrm{s}$ & $13.16 \mathrm{~m} / \mathrm{s}$ \\
\hline $3 \mathrm{~mm}$ & $4.38 \mathrm{~m} / \mathrm{s}$ & $4.93 \mathrm{~m} / \mathrm{s}$ & $8.77 \mathrm{~m} / \mathrm{s}$ \\
\hline $4 \mathrm{~mm}$ & $3.29 \mathrm{~m} / \mathrm{s}$ & $3.95 \mathrm{~m} / \mathrm{s}$ & $6.58 \mathrm{~m} / \mathrm{s}$ \\
\hline
\end{tabular}

\section{Conclusion}

Thermal safety issues have been the main obstacle to restrict the application of lithium-ion batteries in large size and high energy density development. In the current study, the thermal characteristics of an NCM LIB in the condition of natural convection were comprehensively assessed and experimentally investigated with the infrared imaging (IR) technology. Furthermore, the temperature distribution of battery surface was greatly improved in different directions of air flow. Reciprocating air-flow cooling method was therefore proposed. The experimental results and analysis indicated that reciprocating airflow cooling was an effective method of BTMS, especially in controlling temperature difference. The current study revealed different thermal behaviors under a variety of reciprocating air-flow control strategies and provided a certain reference for the battery thermal management in reciprocating air-flow cooling and relevant research.

The results showed that during the discharge process of natural convection, the overall temperature distribution can be concluded that the part near to the electrode showed the highest temperature, and the lowest temperature region was far from the electrode. Heat generation rate was significantly higher on the electrode side and the maximal surface temperature difference was about $12.2^{\circ} \mathrm{C}$ at $3 \mathrm{C}$ discharge. At the end of discharge process, the high-temperature area showed a downward-moving trend. 
In a non-reciprocating air-flow system, the air flow direction affected temperature distribution to a great extent. The forward air flow case performed better than the backward air flow in both $T_{i n c}$ and $\Delta T_{\max }$ due to the thermal characteristics of batteries. This also revealed that in a non-reciprocating air-flow system for the large pouch cell, forward air flow was always preferred.

Experimental results showed that it was not effective to prevent temperatures difference from increasing by starting air reciprocation at an early stage of discharge. However, in the 50\% DOD case, the curve of temperatures difference was most ideal. Compared to other cases, it had the lowest temperatures difference in a large proportion of DOD. Therefore, reciprocating air-flow started from middle stage of DOD was recommended.

In the isochronous cycles, the extension of $\mathrm{T}_{\mathrm{f}}$ period can decrease the temperature difference efficiently, giving a valuable clue for further development of aperiodic cycles. In the aperiodic cycles, the temperature distribution was almost ideal by means of optimized control strategy set according to actual circumstances, with $\Delta T_{\max }$ decreased by $49.5 \%$ and $25.5 \%$ compared to the forward air flow and isochronous case. In the optimized case $\Delta T_{\max }$ was mainly caused by a small area of the low temperature and $T_{\text {Var }}{ }^{2}$ was remarkably decreased indicating that reciprocating air-flow had effect on balancing the overall temperature distribution. Meanwhile a stricter requirement of temperature difference can be achieved by optimized control strategy, indicating that a higher reversing frequency and lower response time of system was needed.

Finally, reciprocating air-flow had conspicuous and positive impact on smoothing temperature distribution but limited effect on $T_{i n c}$, the maximum temperature of battery cannot be improved by only relying on reciprocating air-flow or its control strategy. $T_{i n c}$ can be restrained by adjusting the flow rate and thickness of air channel. The maximum temperature rise decreased with increased air flow rate, and under a certain air flow rate the thinner channel showed better performance on $T_{i n c}$. However, in the terms of temperature difference, both thinner channel and higher rate flow had an adverse effect.

\section{Acknowledgments}

The work is supported by De Montfort University through its distinguished Vice-Chancellor 2020 Programme, UK Science and Technology Facilities Council (STFC) through Batteries Early Career Researcher Award and the Ministry of Science and Technology of China through the Programme of International Cooperation (2016YFE0118600).

\section{References}

[1] Pesaran AA. Battery thermal management in EVs and HEVs: issues and solutions. Battery Man 2001; 43:34-49.

[2] Kohno K, Koishikawa Y, Yagi Y, Horiba T. Development of an Aluminium-laminated Lithium-ion battery for Hybrid electric vehicle application. J. Power Sources 2008;185(1):554-558.

[3] Kizilel R, Lateef A, Sabbah R, Farid M, Selman J.R, Al-Hallaj S. Passive control of temperature 
excursion and uniformity in high-energy Li-ion battery packs at high current and ambient temperature. J. Power Sources 2008;183(1):370-375.

[4] Wei Y, Agelin-Chaab M. Experimental investigation of a novel hybrid cooling method for lithiumion batteries. Appl. Therm. Eng. 2018;136:375-87.

[5] Rao Z, Wang Q, Huang C. Investigation of the thermal performance of phase change material/minichannel coupled battery thermal management system. Appl. Energ.2016;164:659-69.

[6] Wang Q, Rao Z, Huo Y, Wang S. Thermal performance of phase change material/oscillating heat pipe-based battery thermal management system. Therm. Sci. 2016;102:9-16.

[7] Wu W, Yang X, Zhang G, Chen K, Wang S. Experimental investigation on the thermal performance of heat pipe-assisted phase change material based battery thermal management system. Energ. Convers. Manage. 2017;138:486-92.

[8] Zhao L, Yu X, Wei L, Qiu Y, Zhang L, Meng X, et al. Parametric study of forced air cooling strategy for lithium-ion battery pack with staggered arrangement. Appl. Therm. Eng. 2018;136:28-40

[9] Wang T, Tseng KJ, Zhao J, Wei Z. Thermal investigation of lithium-ion battery module with different cell arrangement structures and forced air-cooling strategies. Appl. Energ. 2014;134: 229238.

[10]Fan L, Khodadadi JM, Pesaran AA. A parametric study on thermal management of an air-cooled lithium-ion battery module for plug-in hybrid electric vehicles. J. Power Sources 2013;238: 301312.

[11] Giuliano MR, Prasad AK, Advani SG. Experimental study of an air-cooled thermal management system for high capacity lithium-titanate batteries. J. Power Sources, 2012;216:345-352.

[12] Zhu C, Li X, Song L, Xiang L. Development of a theoretically based thermal model for lithium ion battery pack. J. Power Sources 2013;223:155-64.

[13] Mahamud R, Park C. Reciprocating air flow for Li-ion battery thermal management to improve temperature uniformity. J. Power Sources 2011;196:5685-96.

[14] Yu K, Yang X, Cheng Y, Li C. Thermal analysis and two-directional air flow thermal management for lithium-ion battery pack. J. Power Sources 2014;270:193-200.

[15] Lu Z, Meng XZ, Wei LC, Hu WY, Zhang LY, Jin LW. Thermal management of densely-packed EV battery with forced air Cooling Strategies. Energy Procedia 2016;88:682-8.

[16] Liu Y, Ouyang C, Jiang Q, Liang B. Design and parametric optimization of thermal management of lithium-ion battery module with reciprocating air-flow. Journal of Central South University 2015;22: 3970-3976.

[17] Na X, Kang H, Wang T, Wang Y. Reverse layered air flow for Li-ion battery thermal management, Appl. Therm. Eng. 2018;143:257-262,

[18] He F, Ma L. Thermal management of batteries employing active temperature control and reciprocating cooling flow. Int. J. Heat Mass Tran. 2015; 83:164-172.

[19] Panchal S, Mathewson S, Fraser R, Culham R, Fowler M. Thermal Management of Lithium-Ion Pouch Cell with Indirect Liquid Cooling using Dual Cold Plates Approach, SAE International Journal of Alternative Powertrains. 2015;4:293-307.

[20] Panchal S, Dincer I, Agelin-Chaab M, Fraser R, Fowler M. Thermal modeling and validation of temperature distributions in a prismatic lithium-ion battery at different discharge rates and varying 
boundary conditions. Appl. Therm. Eng. 2016; 96:190-199.

[21] Saeidi SM, Khodadadi JM . Transient flow and heat transfer leading to periodic state in a cavity with inlet and outlet ports due to incoming flow oscillation. Int. J. Heat Mass Tran. 2007;50:530-538

[22] Khodadadi JM. Oscillatory fluid flow through a porous medium channel bounded by two impermeable parallel plates. Journal of Fluid. Eng.1991;113:511.

[23] Siegel R, Perlmutter M. Heat transfer for pulsating laminar duct flow. Transactions of the ASME. $1962 ; 122$

[24] Kim US, Shin CB, Kim CS. Effect of electrode configuration on the thermal behaviour of a lithiumpolymer battery. J. Power Sources 2008;180(2):909-916.

[25] Dong HJ. Numerical modelling of lithium ion battery for predicting thermal behaviour in a cylindrical cell. Curr. Appl. Phys. 2014;14(2):196-205.

[26] Lee CY, Lee SJ, Chen YH, Chung MY, Han KCh, Chang YM, Tang MS. In-situ Monitoring of temperature and voltage in Lithium-ion battery by embedded flexible micro temperature and voltage sensor. Int. J. Electrochem. 2013;8:2968-2976.

[27]Daud ZHC, Chrenko D, Santos FD, Aglzim EH, Keromnes A, Moyne LL. 3D electro-thermal modelling and experimental validation of lithium polymer-based batteries for automotive applications. Int. J. Energy Res. 2016;40:1144-1154.

[28] Lei Z, Zhang Y, Lei X. Improving temperature uniformity of a lithium-ion battery by intermittent heating method in cold climate. Int. J. Heat Mass Tran. 2018;121:275-281

[29] Wang T, Tseng KJ, Zhao J. Development of efficient air-cooling strategies for lithiumion battery module based on empirical heat source model. Appl. Therm. Eng. 2015;90:521-9.

[30] Yang N, Zhang X, Li G, Hua D. Assessment of the forced air-cooling performance for cylindrical lithium-ion battery packs: A comparative analysis between aligned and staggered cell arrangements. Appl. Therm. Eng. 2015;80:55-65.

[31] Pesaran AA. Battery thermal models for hybrid vehicle simulations. J. Power Sources 2002;110:377382. 